OPEN ACCESS

Edited by:

Frank Adam,

University of Rostock, Germany

Reviewed by:

Andrew J. Goupee,

The University of Maine, United States

Bela H. Buck,

Helmholtz Centre for Polar and Marine

Research (AWI), Germany

*Correspondence:

Maarten Flikkema

M.Flikkema@marin.n

Specialty section

This article was submitted to

Ocean Solutions,

a section of the journal

Frontiers in Marine Science

Received: 03 June 2019

Accepted: 22 August 2019

Published: 10 September 2019

Citation:

Flikkema M and Waals O (2019)

Space@Sea the Floating Solution.

Front. Mar. Sci. 6:553.

doi: 10.3389/fmars.2019.00553

\section{Space@Sea the Floating Solution}

\author{
Maarten Flikkema* and Olaf Waals
}

MARIN, Wageningen, Netherlands

This paper describes the Horizon 2020 project Space@Sea (www.spaceatseaproject.eu) which started in November 2017. This project aims to provide a concept of affordable and flexible floating islands. With increasing population and rising sea level there is a scarcity for space on land for the people to live, grow food and harvest renewable energy. Moreover, a large number of people live in areas that are exposed to the risk of flooding in case of sea level rise. These trends call for a solution at sea that creates a new perspective. Previous projects on floating habitation such as the TROPOS project (www.Troposplatform.eu) have delivered artist impressions. Technical solutions are yet to be provided. In the Space@Sea project a conceptual study is done to develop a standardized floating solution for offshore space. Four applications focusing on energy hub, living, aquaculture and maritime transport will be demonstrated. For two locations a business case of a combination of these applications will be examined. The present paper discusses the Space@Sea project background and approach of the collaborative research. First results regarding the basic design and societal acceptance are discussed at a high level. Throughout the Space@Sea project results will be published on Frontiers in Marine Science.

Keywords: floating islands, renewable energy, living at sea, logistics hub, aquaculture, Horizon 2020

\section{INTRODUCTION}

The majority of the world population lives in coastal areas where space has always been a commodity; available land space is limited. In the near future the waterfront may reclaim or change the utilization of large parts of existing land space as the sea level rises with global warming. There is thus an increasing interest to evaluate the merits and challenges for the use of ocean space. The European Commission has recognized this challenge in their Horizon 2020 research program (European Commission, 2017) and has called to turn the seas and oceans into an asset for Europe.

Simultaneously offshore activities are growing rapidly from the traditional oil and gas applications to renewable energy, aquafarming, transportation hubs, tourism, airports and city extensions (Schultz-Zehden et al., 2018). These vary from relatively close to shore to further offshore activities. Traditionally offshore activities are either done on a dedicated working platform or on an artificially created island. Large floating solutions where multiple activities are combined have yet to be applied. Floating island concepts are the next step in existing offshore floating technology. Existing knowledge can be used, however there are still technological barriers to be challenged. For example, the behavior of multi body interaction of a large number of floaters together has to be investigated. 
One of the main benefits of the floating solution is the low ecological impact. Where gravity based artificial islands heavily interfere with the environment, floating solutions, apart from potentially the anchoring, have no permanent impact on the environment. Floating islands can be used for temporary applications but should be robust enough to be a permanent solution. Figure 1 shows an impression of a combined energy and transport hub. A modular approach to floating islands provides flexibility in adding or removing deck space and functionalities when required. For instance, during the installation of an offshore wind farm, more space for housing people and construction material is required than when the wind farm is in operation.

In November 2017, 17 partners in the Space@Sea consortium (see text footnote 1) set out to provide sustainable and affordable workspace at sea by developing a standardized and cost-efficient modular island with low ecological impact. A generic floater will be developed on which a wide variety of applications can be placed. Within the Space@Sea project the research is limited to, four applications:

(1) Energy servicing and generation hub

(2) Living for workers and urban extension

(3) Aquaculture

(4) Maritime transport and logistics hub.

The business case for each application will be studied individually as well as in combination with the other applications for selected locations. Space@Sea will conclude in a scale demonstration of the combined business cases demonstrating the concept of modular floating islands and their potential.

In this paper the Space@Sea project is introduced by providing insight in the background of the project, the chosen approach to achieve the project objectives and the expected results and impact.

\section{BACKGROUND}

The concept of floating islands is not new. In many research projects artist impressions have been made and case studies into the societal acceptance and economic feasibility have been done. From the European 7th framework program (FP7) call "the Oceans of Tomorrow" a number of new island concepts were developed for various purposes. As an example, the TROPOS project (see text footnote 2 ) has successfully developed unique concepts for Transport, Energy, Aquaculture and Leisure.

Horizon 2020 project MUSES looked into multi-use of ocean space where various activities can be done in the same area. This can be in or on the water, but also on islands, floating or gravity based. Applications such as tourism, fishery, aquaculture, wind farms, renewable energy generation and environmental protection have been studied. A multi-use action plan was delivered at the conclusion of the project (Schultz-Zehden et al., 2018).

In the summer of 2017 MARIN developed a modular floating island concept with triangular floaters. Model tests have been done with this concept as shown in Figure 2. These tests were initiated by MARIN as a first study to show the behavior of a large modular floater. The results of the model tests were published by Waals et al. (2018). The large island (the Figure 2 example has a total size of $1.5 \mathrm{~km}$ by $2 \mathrm{~km}$ ) consists of triangular floaters to allow flexibility in multiple directions. Due to the flexible couplings these triangular modules are free to move in respect to each other, making the island drape over the waves like a carpet. The hypothesis was that this would lead to less severe connection forces between the modules.

\section{APPROACH}

With the triangular concept as a starting point MARIN together with the 16 other partners initiated the Space@Sea project as part of the European Horizon 2020 research program. Modularity is one of the key elements of the Space@Sea concept.

Probably the most well-known concept of modular design is the popular Danish toy LEGO. Blocks of relatively few different shapes and sizes can be put together to build anything one can imagine. In the transport sector standardization and modularity was initiated through the introduction of the shipping container. By using standard dimensions for the containers, building of ships and train and truck trailers has become significantly less expensive resulting in a boost of the transport market. Over 90\% of the world-wide containers belong to the family of 20 or 40 foot containers.Space@Sea will follow the analogy of standardization for the size as well as the choice to make the larger container a multitude in size of the smaller container. In this way Space@Sea intends to significantly reduce the building and installation costs and provide the desired flexibility for use of the deck space at sea.

Two sizes of building blocks will be designed, where a multitude of the smaller blocks fit in one bigger block. This is comparable to the aforementioned transport containers where in general two sizes are available, a 40 foot container and a 20 foot container. Figure 2 shows that for the first tests in 2017, the 7 larger islands in the center had double the side length compared to the triangle floaters on the outer edges. Here it is important that the connection points between the floaters support this modularity.

In principle any activity can take place on the individual blocks as long as there is a business case for it. Space@Sea will focus on four types of applications which will be demonstrated during the course of the project. These applications are:

- Energhub@Sea: The energy hub component not only facilitates the possibility to generate renewable energy from the relative motions between the floaters, but also provides space for servicing of renewable energy offshore parks. A method to harvest energy from the relative motions between the floaters will be developed. This is expected to reduce motions further down in the interior of the structure. As part of the servicing function, storage and housing for workers is foreseen as well as a center for distributing the energy to shore.

- Living@Sea: In the previous century, the Netherlands won back land from the sea. These so called polders were primarily used for farming but rapidly after the farms were 


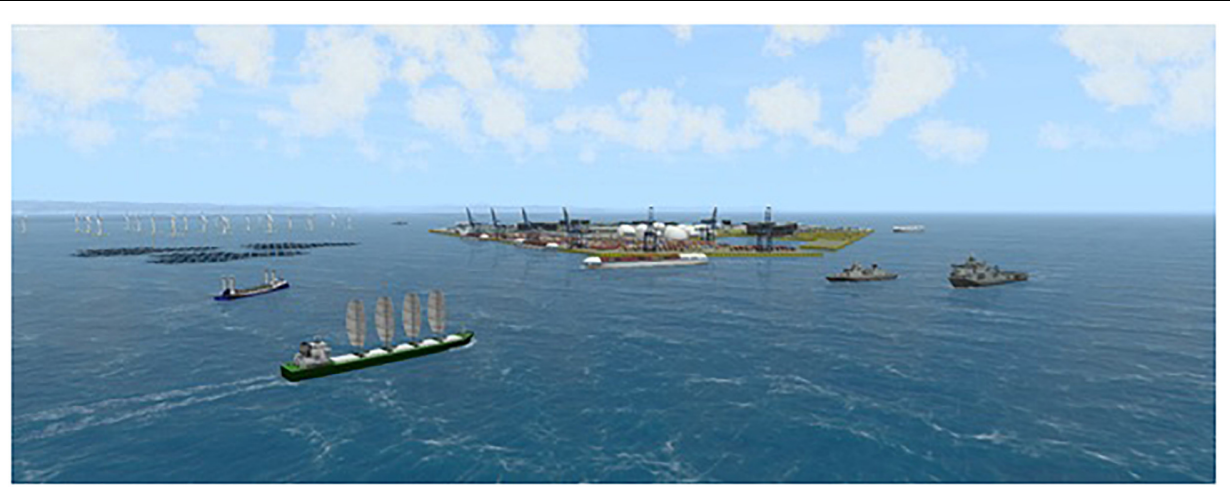

FIGURE 1 | Impression of a floating energy and logistics island.

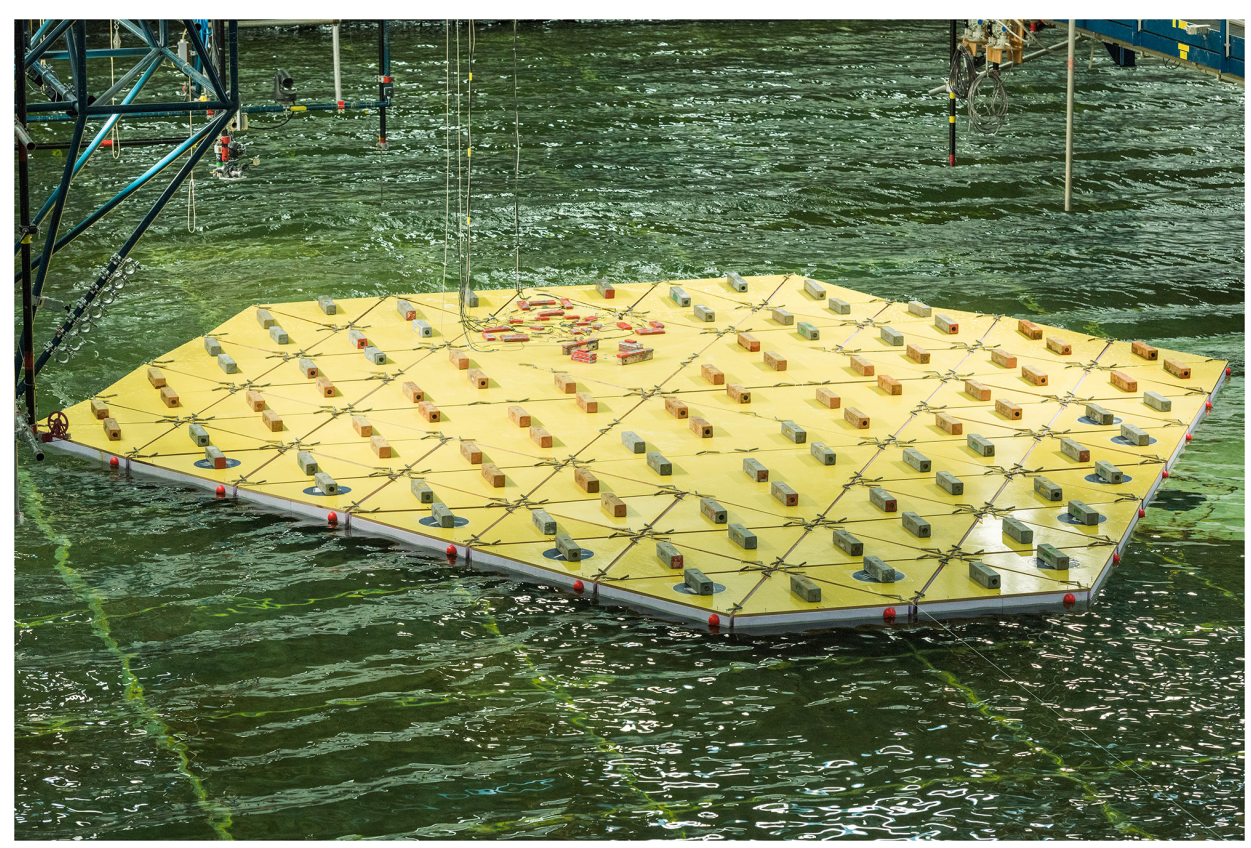

FIGURE 2 | Initial model test of the multi-use platform concept with equilateral triangles.

established, the first people moved to the polders, now facilitating several cities. It is the philosophy of Space@Sea that jobs at sea will attract people to live at sea too. The demand is already visible for maintenance crew of offshore renewable energy. It is too costly to move the crew for each task separately creating a demand for hotel space at sea. This concept will start from housing for workers in the near future but expand through housing for the families to larger building complexes and cities to be placed on the islands.

- Farming@Sea: Aquaculture is playing an ever increasing role in both food and energy production. Energy can be harvested as bioenergy from crops grown offshore while these crops can also add to the food production. Also, fish farming further offshore is becoming feasible. In Space@Sea the farming component will be developed in order for the floating islands to become self-sustaining.
-TransporteLogistics@Sea: With growing transport quantities, ports will require more space. Rotterdam has solved this problem for now by expanding into the North Sea. This solution is rather costly and may not be applicable for all harbors. For city ports which have limited space to extend such as Constanta, Barcelona or Gibraltar, an offshore hub will be the only possibility for growth. For ports like Hamburg and Antwerp a logistic hub offshore will provide the possibility to extend the port activities without the necessity of many large ships navigating the narrow river. The Transport\&Logisitcs@Sea component will cater for such possibilities.

The analogy with the aforementioned LEGO building blocks is continued in the Space@Sea project structure shown in Figure 3. Technical work is divided in 10 work packages which are 


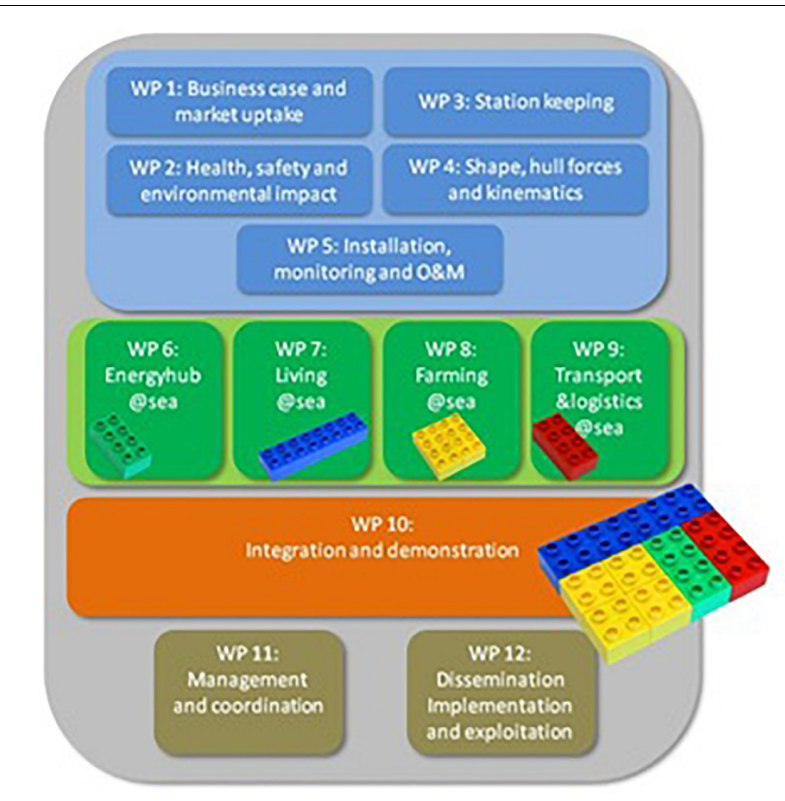

FIGURE 3 | Space@Sea project structure.

grouped in clusters. One cluster coping with generic issues and technologies which are irrespective of the application, a cluster dealing with the development of the various applications themselves and an integration and demonstration cluster. This is supported by a cluster consisting of management, dissemination and implementation work.

Generic issues address those issues which concern the floater design, which are marginally affected by the activities on the floater. Activities on the platform set the boundary conditions and requirements for the design of the floaters. These activities comprise the design of the floater and the hydrodynamic behavior as well as the mooring and interconnection between the individual floaters. Health and safety issues are addressed considering an evaluation of the existing regulations and identification of needs for regulations. Installation, condition monitoring and operation \& maintenance are considered as a critical component.
Aside from the generic issues and technologies, each application has specific challenges to cope with. This includes the respective designs and developments so that each component will be validated in a relevant environment Technology Readiness Level (TRL), similar to the tests performed by MARIN (Waals et al., 2018).

All work from the previous sections will lead into integration and demonstration where all work is brought together. All the applications are integrated into the final design of the demonstrators. Demonstration of the Space@Sea concept will be done at scale in controlled real life environmental conditions accounting for wind, waves and current induced effects. A controlled demonstration is done at the MARIN model testing facilities (Figure 2) where the real environmental conditions at the different locations which are part of the business cases can be simulated.

\section{RESULTS AND EXPECTED IMPACT}

The aforementioned approach will lead to tangible results during the three year project with the main result being the demonstrated modular floating island concept and evaluation of the business cases. During the demonstration a variety of controlled environmental conditions will be tested, from normal operation to extreme conditions. The demonstrator will have the activities on top of each floater modeled visually. For instance, in the case of living at sea, the actual housing blocks will be built. This gives an overview of the floating city and the urban planning.

Two business cases are evaluated in Space@Sea which will determine the layout of the islands for the demonstrator. The locations are shown in Figure 4, the transport and logistics hub will be placed outside of the Schelde river to support the port of Antwerp. Transport and logistic activities are combined with living facilities and aquaculture. In the Mediterranean an energy hub will be placed from where wind parks can be serviced. This is combined with aquaculture and the generation of wave energy.

One of the first topics in the project was the basic design of the floater, focusing on the shape and main dimensions. Where in the research leading to the Space@Sea project triangular
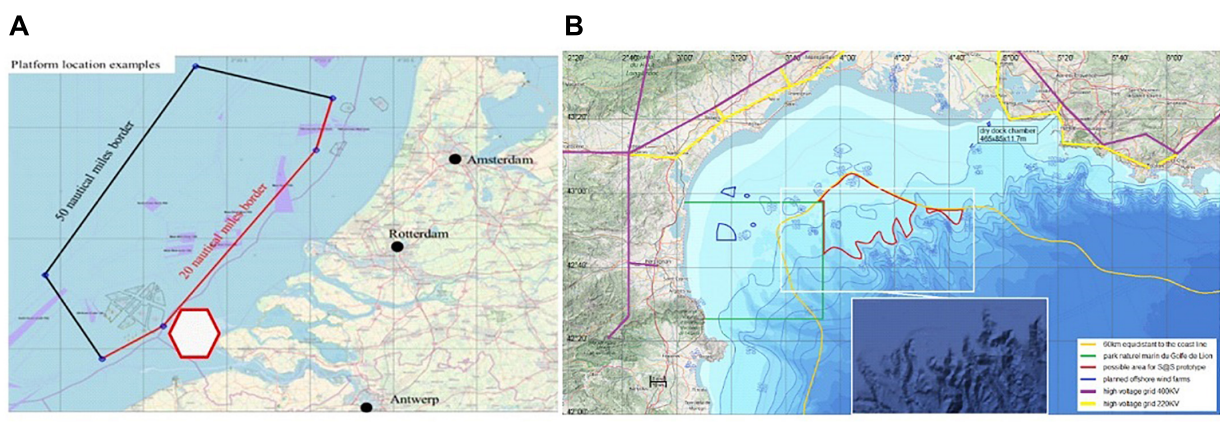

FIGURE 4 | Business case locations, North Sea (A) and Mediterranean (B). 
floaters were used, the analysis also studied alternative shapes. Otto et al. (2019a,b) show that equilateral triangles indeed show lower connection loads than square pontoons in oblique sea states. Although equilateral triangles have generally lower loads, for specific relative wave angles the results still show a peak in the connection forces. Criteria regarding connection forces were weighed against usability and manufacturability of the floaters. This resulted in the choice for rectangular floaters, which from a space efficiency point of view are favorable. Individual floaters have a size of $45 \mathrm{~m}$ square for the small floater and $90 \mathrm{~m}$ square for the large floater. Details of the basic design will be published in more detail in a future paper on the Frontiers in Marine Science.

One of the most important results of the project, although not tangible, is the discussion on increased activities at sea and the accompanying guidelines and regulations. Currently there are no regulations regarding non-working activities on floating offshore platforms, the regulations from the oil and gas industry are the most complete but could also be quite strict for many other activities. Space@Sea has made an inventory of regulations as a starting point (Köpke et al., 2018). A new discussion on regulations for a wide variety of offshore activities needs to be started, this however will not start without a clear concept of (floating) offshore activities. The Space@Sea concept will be used to start up the discussions between designers, users, regulatory bodies and members states.

Many of the Space@Sea technical developments also contribute to technical developments in related sectors. Knowledge and experience gained in the shared mooring approach developed in WP 3 can be applied when designing mooring systems of floating wind turbines. Also, the technology for connecting the floaters to each other can have many different applications in shipping and offshore.

Space@Sea results will have a positive impact on maritime and offshore activities through an increased economic viability of multi-use offshore activities on modular floating islands. Modularity is one of the key elements in reducing the costs of floating islands. No new floater design needs to be made for new applications and manufacturing can be standardized. For offshore operations moorings are one of the key cost components, however standardization in mooring is challenging due to the variation of environmental conditions for potential locations for floating islands. Developments in Space@Sea will study shared mooring for the various floaters where the total floating island is moored and not each individual floater. This will lead to significant reductions not only for manufacturing and installation but also during the exploitation phase. Interconnections facilitate the possibility to increase the size of the island by adding new floaters if the demand for more deck space arises. The authors realize that the long term operation of large mooring systems have their own challenges such as fatigue and corrosion.

Compared to current day offshore activities, Space@Sea floating island solution provides a more stable platform for the work. It is the aim to have the floating islands have minimal motions, providing a working or living surface close to that on shore. With this the health and safety conditions for offshore workers is greatly improved. Safety issues regarding traveling between floaters will be considered by flexible bridges. Living conditions for people on the floating islands will be close to those onshore, positively impacting the comfort of the workers.

In order to achieve this the concept of living and working at sea for longer periods on end needs to be accepted. Dedicated activities aim at improving the social acceptance. One of these activities is a continued interaction with a stakeholder group of people already working offshore. In 2018 a survey was done (Lüthje, 2018) to obtain the perspective of future inhabitants of floating islands. In this primary survey people already working offshore on ships or offshore stations with various backgrounds were interviewed. The survey indicated that for an elongated stay at sea, better leisure facilities need to be present. Almost all participants agreed that the number of community members on the platform should be larger than the number of crew members on a freighter or container vessel. Participants to the survey indicated that they foresee a "whole city on a platform" with living conditions close to those on the mainland. The same group, as well as additional groups, will be involved in future surveys where impressions of life at sea will be used to provide a clear picture of what can be expected.

\section{CONCLUDING REMARKS}

The three year Horizon 2020 funded research project Space@Sea is well underway. Partners are developing a standardized modular floating island, aiming at providing affordable deck space at sea. The project started in November 2017 and the first results have been published through the internet site (see text footnote 1). In this special edition of Frontiers in Marine Science intermediate results will be published in peer reviewed papers. Topics of the papers cover the broad scope of the project such as the numerical simulations and model tests, floater and mooring design, remote monitoring, the design of the four applications, the final integration and demonstration and the resulting business cases analysis. All papers are to be expected at regular intervals until the end of the project.

One of the main outcomes of Space@Sea is the start of discussions on rules and regulations for offshore floating islands. These discussions are necessary for further developments of floating islands and multi-use of ocean space. Sooner or later, the regulatory bodies like the International Maritime Organization (IMO) and Classification Societies or Flag Authorities will need to look into regulations for floating islands (for multiple applications such as living, transport and logistics, aquaculture and energy production and maintenance) as the economic reality will ask that. At present the discussion is theoretical as there is no concept floating island to talk about. With the (intermediate) results of Space@Sea these discussions can focus on an actual case. Even if the final floating island has little resemblance with the Space@Sea concept, it is this concept which will accelerate the discussions. Space@Sea partners are involved in many developments and discussions on floating islands and present the modular concept as an opportunity. 


\section{AUTHOR CONTRIBUTIONS}

Both authors listed have made a substantial, direct and intellectual contribution to the work, and approved it for publication.

\section{FUNDING}

Space@Sea partners received a total of $€ 6,766,793.02$ funding from the European Commission as part of the Horizon 2020

\section{REFERENCES}

European Commission (2017). Commission Staff Working Document - Report on the Blue Growth Strategy Towards More Sustainable Growth and Jobs in the Blue Economy. Brussels: European Commission.

Köpke, K., Lindeboom, R., and Jak, R. G. (2018). Inventory of Regulations, Space@Sea Deliverable 2.1 (Public). Available at: https://spaceatsea-project.eu/ public-information/public-deliverables (accessed September 3, 2019).

Lüthje, C. (2018). List of Functional Requirements for the Design, Space@Sea Deliverable 7.1 (Public). Available at: https://spaceatsea-project.eu/publicinformation/public-deliverables (accessed September 3, 2019).

Otto, W., Waals, O., Bunnik, T., and Ceneray, C. (2019a). "Wave induced motions of a floating Mega Island," in Proceedings of the World Conference on Floating Solutions, Singapore.

Otto, W. J., Waals, O. J., Bunnik, T. H. J., and Cresp, J. (2019b). “Optimization of Wave Induced Motions and Forces on a Floating Island," in Proceedings of the The 29th International Ocean and Polar Engineering Conference, (Honolulu, HI: International Society of Offshore and Polar Engineers). research program under grant number 774253. Space@Sea was funded under Research and Innovation call H2020-BG-04-2017. The opinions in this document reflect only the author's view and in no way reflect the European Commission's opinions. The European Commission is not responsible for any use that may be made of the information it contains. Space@Sea is a partnership between the following partners: MARIN, DeltaSync, DST, NEMOS, TU Delft, MOCEAN, TU Hamburg Harburg, Bluewater, University Rostock, GICON, Wageningen University Research, University Duisburg Essen, TU Graz, Waterstudio, Icepronav, VAL FoU and GeoSea.

Schultz-Zehden, A., Lukic, I., Onwona, A. J., Altvater, S., Bamlett, R., Barbanti, A., et al. (2018). Ocean Multi-Use Action Plan, MUSES Project. Edinburgh: MUSES.

Waals, O. J., Bunnik, T. H. J., and Otto, W. J. (2018). "Model tests and Numerical Analysis for a Floating Mega Island," in Proceedings of the ASME 2018 37th International Conference on Ocean, Offshore and Arctic Engineering, OMAE2018-78589, Madrid.

Conflict of Interest Statement: MF is coordinator of the Horizon 2020 project Space@Sea. OW is one of the technical initiators of the Space@Sea project.

Copyright (C) 2019 Flikkema and Waals. This is an open-access article distributed under the terms of the Creative Commons Attribution License (CC BY). The use, distribution or reproduction in other forums is permitted, provided the original author(s) and the copyright owner(s) are credited and that the original publication in this journal is cited, in accordance with accepted academic practice. No use, distribution or reproduction is permitted which does not comply with these terms. 